OPEN ACCESS

Edited by:

Pietro Gareri,

ASP Catanzaro, Italy

Reviewed by:

Nicola Veronese,

University of Palermo, Italy

Andrea Corsonello,

National Institute of Science and Health for Aging (INRCA-IRCCS),

Italy

${ }^{*}$ Correspondence:

Xiaocui Cao

caoxiaociu@126.com

Chunhua Ma

mawinter@126.com

tThese authors have contributed equally to this work and share first authorship

Specialty section:

This article was submitted to Psychology for Clinical Settings,

a section of the journal

Frontiers in Psychology

Received: 14 April 2021 Accepted: 08 November 2021 Published: 14 December 2021

Citation:

Cao X, Wu J, Gu Y, Liu X, Deng Y and Ma C (2021) Post-traumatic Stress Disorder and Risk Factors in Patients With Acute Myocardial

Infarction After Emergency Percutaneous Coronary Intervention:

A Longitudinal Study.

Front. Psychol. 12:694974. doi: 10.3389/fpsyg.2021.694974

\section{Post-traumatic Stress Disorder and Risk Factors in Patients With Acute Myocardial Infarction After Emergency Percutaneous Coronary Intervention: A Longitudinal Study}

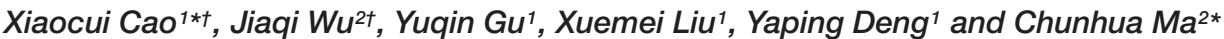 \\ ${ }^{1}$ Department of Cardiovascular Medicine, The Second Affiliated Hospital of Guangzhou Medical University, Guangzhou, \\ China, ${ }^{2}$ School of Nursing, Guangzhou Medical University, Guangzhou, China
}

This study aimed to investigate the status and risk factors of post-traumatic stress disorder (PTSD) in patients with acute myocardial infarction (AMI) after emergency percutaneous coronary intervention $(\mathrm{PCl})$ in acute and convalescence phases. A longitudinal study design was used. Two questionnaire surveys were conducted in the acute stage of hospitalization, and 3 months after onset in patients. Logistic regression was used to analyze the risk factors for PTSD in AMI patients. The incidence of PTSD was 33.1 and $20.4 \%$ in acute and convalescent patients, respectively. The risk factors related to PTSD were door-to-balloon time (DTB) ( $\geq 92.6 \mathrm{~min}$ ), left ventricular ejection fraction (LVEF) (<50\%), smoking, anxiety, and depression. AMl patients after $\mathrm{PCl}$ had PTSD in the acute and convalescent stage. The findings indicate that tailored measures should be developed and carried out to prevent PTSD and improve the mental health of patients with $\mathrm{AMl}$ after undergoing $\mathrm{PCl}$.

\footnotetext{
Keywords: acute myocardial infarction, anxiety, depression, percutaneous coronary intervention, post-traumatic stress disorder
}

\section{INTRODUCTION}

Acute myocardial infarction (AMI) is a common and serious heart disease with rapid onset, extremely high morbidity, and mortality (Reed et al., 2017). Approximately 50\% of AMI patients have multivessel coronary artery disease (Saito and Kobayashi, 2019). The key to successful AMI treatment is to open the infarct-related artery as soon as possible, and emergency percutaneous coronary intervention (PCI) is the mainstay of treatment for AMI patients (Levine et al., 2016). Post-traumatic stress disorder (PTSD) is defined as a stress-related disorder with a subsequent autoimmune disease that might arise after exposure to a serious traumatic event or injury (Liang et al., 2020). Previous studies have shown that approximately $12 \%$ of AMI patients developed PTSD (Edmondson et al., 2012), and 66.7\% of patients had PTSD symptoms 2 years after AMI (Castilla and Vázquez, 2011). The abruptness of the event, the risk of death, and the patient's intense sense of loss of control and helplessness during the event as well as the intrusive experience of the treatments, such as PCI, could lead to the development of PTSD (Ledermann et al., 2020). 
In addition, the occurrence of PTSD after emergency PCI is associated with poor therapeutic efficacy, such as repeated rehospitalization, multiple complications, and increased mortality (Guler et al., 2009; Edmondson et al., 2012; Sumner et al., 2015; Burg and Soufer, 2016). Therefore, approximately $18-23 \%$ of patients with AMI, who perceived the event as life-threatening and distressing, showed clinically relevant acute stress symptoms (Ledermann et al., 2020). AMI is a stressful traumatic event, and AMI patients usually have a severe psychologically traumatic experience that endangers their lives. Recently, an increasing number of studies have explored AMI-related PTSD (Edmondson et al., 2011; Perkins-Porras et al., 2015; Singh et al., 2017; Birk et al., 2019). Previous study (Meli et al., 2019) showed that invasive treatment was a risk factor for PTSD in AMI patients, and AMI patients that received invasive surgery were more prone to develop PTSD symptoms than those that received conservative treatment. PTSD after AMI could cause prolonged psychological pain and increase the risk of major adverse cardiac events, which results in impaired quality of life (Känel et al., 2011; Edmondson and von Känel, 2017).

Some studies found that the occurrence of PTSD in AMI patients might be related to the patient's social demographic factors (e.g., age, gender, and race), disease factors, socioeconomic factors, psychological factors (e.g., anxiety and depression), and personality (e.g., introversion and impulsive personality traits) (Wikman et al., 2008; Hari et al., 2010; Roberge et al., 2010; Dinenberg et al., 2014; Oflaz et al., 2014; Stevanović et al., 2016). Previous studies found that depression was strongly associated with the development of PTSD and comorbidity and that depression (hospitalization or before onset) was predictive of PTSD (Whitehead et al., 2006; Roberge et al., 2010). Konrad et al. (2017) reported that several environmental factors in emergency departments influenced a patient's perception of threat to life, and increased risk for subsequent PTSD in AMI patients. Many patients showed a strong fear of dying after the onset of acute symptoms, and emotional distress is common in approximately one-third of patients that reported mild-to-moderate depressive symptoms post-hospitalization for AMI (Wikman et al., 2008).

Currently, the number of AMI patients after discharge that have PSTD symptoms is difficult to assess, and the diversity of symptoms means that it is difficult to determine the progression of PSTD and evaluate the effectiveness of treatment. Therefore, this study adopted a longitudinal study design to investigate PTSD and the risk factors in AMI patients following emergency PCI during the in-hospital acute stage and at-home convalescent stage. The results could mean that is it possible to identify patients at risk and help to improve postoperative nursing.

\section{MATERIALS AND METHODS}

\section{Study Design and Procedures}

A longitudinal design was used in this study. AMI patients that were admitted to the University Hospital, Guangzhou, Southern China, between September 1, 2019, and March 31, 2020, and were successfully implanted with coronary stents by emergency PCI were enrolled in this study.
Patients that had all the following were included in this study: (1) AMI and emergency PCI; (2) aged $\geq 18$ years; (3) no other major traumatic events in the previous 6 months, such as car accidents and family changes; (4) willingness to participate in the survey; and (5) clear consciousness, no cognitive impairment, capacity to communicate using language or text. The following patients were excluded from this study: (1) patients that needed to be transferred to ICU for treatment due to serious illness after PCI; (2) patients that had severe hepatic and renal insufficiency and malignant tumors; (3) patients that had a previous mental illness, such as dementia, anxiety, depression, or a family history of mental illness; (4) patients that had a respiratory infection, urinary tract infection, and other serious infectious diseases, and (5) patients that received coronary artery bypass graft surgery.

The sample size of this study was estimated based on the previous study (Xiao, 2008). The PTSD scale consisted of 17 items, each item for five cases at least, considering $15 \%$ nonresponse, a minimum of sample size was 98. 113 AMI patients completed two times survey, which achieved the requirements of sample size.

\section{Instruments}

\section{Demographic and Baseline Clinical Data}

Demographic and baseline clinical data for patients included gender, age, level of education, marital status, smoking history, body mass index (BMI), baseline clinical characteristics (e.g., history of hypertension, diabetes, and hyperlipidemia), chest pain center time index and door-to-balloon (DTB), infarction area, number of coronary artery stenoses, and left ventricular ejection fraction (LVEF).

\section{PTSD Checklist-Civilian Version}

The scale (Känel et al., 2011) to evaluate PTSD was developed by the PTSD research center in the United States, which includes three characteristic syndromes: (1) re-experience (5 items); (2) avoidance (7 items); and (3) hypervigilance (5 items), with 17 items in total (Li et al., 2010). Each item was used with a five-point Likert scale, with a total score from 17 to 85 . The higher the score, the more probable the patient was to develop PTSD. Cronbach's regression coefficient for the scale was 0.87 . According to a previous study, a total score $\geq 44$ suggested the presence of the symptoms of PTSD (Li et al., 2010).

\section{Hospital Anxiety and Depression Scale}

The hospital anxiety and depression scale (HADS) was used to assess the mental state of patients. The HADS scale has good predictive accuracy for anxiety and depression patients and can be used for patients without the participation of psychologists or psychiatrists (Reed et al., 2017). The HADS consists of two subscales (1) anxiety (A); and (2) depression (D), each has seven items, and each item is divided into four grades from 0 to 3 . A score from 0 to 7 indicated no depression or anxiety, from 8 to 10 indicated depression or anxiety, from 11 to 14 indicated possible moderate depression or anxiety, and from 15 to 21 indicated severe depression or anxiety. Cronbach's regression coefficient for the scale was 0.83 . 


\section{Procedure}

Acute myocardial infarction patients that underwent emergency PCI were screened by two trained research assistants based on electronic medical records and clinical recommendations. Researchers conducted unified training for investigators before data collection. Patients that had a lower educational level, older age, or visual impairment had each item explained in detail to ensure that they understood the meaning of each item clearly.

The first survey was conducted between days 1 and 3 after patients were stabilized during the acute hospitalization stage after emergency PCI. Face-to-face PCL-C and HADS questionnaires were conducted and the participants' medical record number and telephone number were recorded to track the patient's condition. The second survey was conducted during athome convalescence ( 3 months after the onset of the disease). PCL-C and HADS questionnaires were conducted again by telephone. Each survey lasted approximately 5-10 min, and the investigators only asked questions and explained the meaning of the questions; however, they did not help the patients to make the choices.

\section{Statistical Analyses}

SPSS 20.0 statistical software was used for data analysis. Data processing included the elimination of questionnaires that had an information missing rate of $>10 \%$ or that had the same answers but with obvious problems. Continuous variables were described by mean and standard deviation, and classified variables were described by frequency and percentage. Continuous variables and categorical variables were compared using a $t$-test and a Chisquared test, respectively. Associated risk factors for PTSD were analyzed using a logistic regression model. All hypothesis tests were bilateral tests. A $p$-value $<0.05$ indicated that the difference was statistically significant.

\section{RESULTS}

\section{General Demographic Characteristics}

After application of the inclusion and exclusion criteria, a total of 129 AMI patients were enrolled in this study. In this study, at stage T1, 129 questionnaires were issued, and 121 valid questionnaires were collected, eight questionnaires had missing information, which included three patients that had missing HADS data, three patients that had missing PCL-C data, and two patients that had experienced deteriorating conditions and had been transferred to ICU for treatment. Therefore, 121 patients presented valid questionnaires at this stage. At stage T2, 113 valid questionnaires were followed up by telephone, eight patients were lost during follow-up. Among eight lost participants, one patient died in the ICU because of illness deterioration, four patients did not answer the telephone, and three patients could not complete the questionnaire by telephone.

At stage T1, the 121 patients included 103 (85.1\%) males and $18(14.9 \%)$ females with an average age of $61.2 \pm 10.7$ years (age range: $36-85$ years). Among these 121 patients, 115 patients (95.0\%) had ST segment elevation myocardial infarction (STEMI) and six patients (5.0\%) had non-ST segment elevation myocardial infarction (NSTEMI). At stage T2, the 113 patients included 95 (84.0\%) males and 18 (26.0\%) females with an average age of $63.7 \pm 10.0$ years (age range: $38-84$ years). Among these 113 patients, 107 patients (94.7\%) had STMEI and six patients (5.3\%) had NSTEMI (Table 1).

\section{Acute and Convalescent Stages of Post-traumatic Stress Disorder}

Out of 121 patients in the acute stage, 40 had PTSD, with an incidence rate of $33.1 \%$ and a PTSD average score of $35.71 \pm 7.52$. Out of 113 patients during the convalescent stage, 23 had PTSD, with an incidence rate of $20.4 \%$ and a PTSD average score of $28.95 \pm 8.4$.

\section{Analysis of Anxiety and Depression in Acute and Convalescent Stages}

During the acute stage, 121 patients had average scores of anxiety and depression of $7.62 \pm 3.56$ and $8.64 \pm 3.54$, respectively, with rates of anxiety and depression of 46.3 and $46.3 \%$, respectively. During the convalescent stage, 113 patients had average scores of anxiety and depression of $6.09 \pm 2.77$ and $7.03 \pm 3.33$, respectively, with rates of anxiety and depression of 41.6 and $45.1 \%$, respectively (Figure 1).

\section{Risk Factors for Post-traumatic Stress Disorder During Acute and Convalescent Stages}

As listed in Table 2, during the acute stage, univariate analysis of PTSD revealed that the risk factors for PTSD included young age [OR $=0.18,95 \%$ CI: $0.08-0.41, p<0.001]$, higher education level $[\mathrm{OR}=5.93,95 \% \mathrm{CI}: 2.59-13.57, p<0.001]$, smoking $[\mathrm{OR}=4.42$, $95 \%$ CI: $1.95-10.00, p<0.001]$, DTB $\geq 92.6 \min [\mathrm{OR}=11.94$, $95 \%$ CI: $4.85-29.43, p<0.001]$, and LVEF $<50 \%$ [OR $=0.25,95 \%$ CI: $0.11-0.58, p=0.001]$. Binary logistic analysis suggested that $\mathrm{DTB} \geq 92.6 \mathrm{~min}[\mathrm{OR}=34.83,95 \% \mathrm{CI}: 8.61-141.00, p<0.001]$ and LVEF $<50 \%$ [OR $=0.08,95 \%$ CI: $0.02-0.30), p<0.001]$ were independent risk factors for PTSD in AMI patients.

During the convalescent stage, univariate analysis revealed that the risk factors for PTSD included young age [OR $=0.20,95 \%$ CI: $0.07-0.60, p=0.004]$, higher education level [OR $=4.57,95 \%$ CI: $1.7-12.31, p=0.003]$, smoking $[\mathrm{OR}=8.21,95 \% \mathrm{CI}$ : $2.57-26.18, p<0.001]$, and LVEF $<50 \%$ [OR $=0.12,95 \%$ CI: $0.05-0.34, p<0.001]$. Multiple factor logistic regression analysis suggested that smoking [OR $=5.12,95 \%$ CI: $1.30-20.16$, $p=0.019]$ and $\mathrm{LVEF}<50 \%$ [OR $=0.08,95 \%$ CI: $0.02-0.28$, $p<0.001$ ] were the independent risk factors for PTSD in AMI patients (Tables 2, 3).

\section{Relationship Between Anxiety, Depression, and Post-traumatic Stress Disorder}

The probability of PTSD symptoms in patients with anxiety and depression symptoms were compared and patients with anxiety and depression symptoms were more probable to have PTSD symptoms (Figure 2 and Table 4). 
TABLE 1 | Demographic and baseline clinical data of patients during acute and convalescent stages.

\begin{tabular}{|c|c|c|c|c|c|c|c|}
\hline \multirow[t]{2}{*}{ Variables } & \multirow[t]{2}{*}{ AMI patients $(n=121)$} & \multicolumn{3}{|c|}{ PTSD during acute stage $(n=121)$} & \multicolumn{3}{|c|}{ PTSD during convalescent stage $(n=113)$} \\
\hline & & No $(n=81)$ & Yes $(n=40)$ & $p^{*}$ & No $(n=90)$ & Yes $(n=23)$ & $p^{\star}$ \\
\hline Age & $61.2 \pm 10.7$ & $64.3 \pm 9.5$ & $54.8 \pm 10.3$ & $<0.001$ & $62.8 \pm 10.2$ & $52.9 \pm 8.9$ & $<0.001$ \\
\hline Gender (age) & & & & 0.109 & & & 0.043 \\
\hline Male & $103(85.1)$ & $66(81.5)$ & $37(92.5)$ & & $72(80.0)$ & $23(100)$ & \\
\hline Female & $18(14.9)$ & $15(18.5)$ & $3(7.5)$ & & $18(18.5)$ & $0(0)$ & \\
\hline $\mathrm{BMI}\left(\mathrm{kg} / \mathrm{m}^{2}\right)$ & $24.1 \pm 1.9$ & $24.0 \pm 2.0$ & $24.3 \pm 1.8$ & 0.414 & $24.0 \pm 1.9$ & $24.3 \pm 2.0$ & 0.629 \\
\hline Degree of education & & & & $<0.001$ & & & 0.002 \\
\hline Junior high school or below & $73(60.3)$ & $60(74.1)$ & $13(32.5)$ & & $60(66.7)$ & $7(30.4)$ & \\
\hline High school or technical secondary school & $48(39.7)$ & $21(25.9)$ & $27(67.5)$ & & $30(33.3)$ & $16(69.6)$ & \\
\hline Marital status & & & & 0.631 & & & 0.287 \\
\hline Married & $100(82.6)$ & $66(81.5)$ & $34(85.0)$ & & $71(78.9)$ & $21(91.3)$ & \\
\hline Divorced or widowed & $21(17.4)$ & $15(18.5)$ & $6(15.0)$ & & $19(21.1)$ & $2(8.7)$ & \\
\hline Smoking & & & & $<0.001$ & & & $<0.001$ \\
\hline No & $65(53.7)$ & $53(65.4)$ & $12(30.0)$ & & $57(63.3)$ & $4(17.4)$ & \\
\hline Yes & $56(46.3)$ & $28(34.6)$ & $28(70.0)$ & & $33(36.7)$ & $19(82.6)$ & \\
\hline Disease diagnosis & & & & 0.177 & & & 0.452 \\
\hline STEMI & $115(95)$ & $79(97.5)$ & $36(90.0)$ & & $84(93.3)$ & $23(100)$ & \\
\hline NSTEMI & $6(5)$ & $2(2.5)$ & $4(10.0)$ & & $6(6.7)$ & $0(0)$ & \\
\hline FMC (min) & $545.2 \pm 918.9$ & $407.6 \pm 677.7$ & $823.8 \pm 1,239.7$ & 0.053 & $595.4 \pm 994.3$ & $379.2 \pm 573.6$ & 0.320 \\
\hline DTB (min) & $92.6 \pm 56.12$ & $69.3 \pm 23.4$ & $139.6 \pm 72.0$ & $<0.001$ & $89.2 \pm 49.8$ & $112.8 \pm 79.2$ & 0.185 \\
\hline Number of coronary artery stenoses & & & & 0.159 & & & 0.815 \\
\hline Single branch & $41(33.9)$ & $24(29.6)$ & $17(42.5)$ & & $29(32.2)$ & $8(34.8)$ & \\
\hline Multiple branches & $80(66.1)$ & $57(70.4)$ & $23(57.5)$ & & $61(67.8)$ & $15(65.2)$ & \\
\hline Area of infarction & & & & 0.202 & & & 0.969 \\
\hline Anterior wall & $38(31.4)$ & $22(27.2)$ & $16(40.0)$ & & $28(31.1)$ & $8(34.8)$ & \\
\hline Inferior wall & $46(38.0)$ & $36(44.4)$ & $10(25.0)$ & & $34(37.8)$ & $8(34.8)$ & \\
\hline Multiple sites & $25(20.7)$ & $15(18.5)$ & $10(25.0)$ & & $18(20.0)$ & $5(21.7)$ & \\
\hline Other sites & $12(9.9)$ & $8(9.9)$ & $4(10.0)$ & & $10(11.1)$ & $2(8.7)$ & \\
\hline LVEF & & & & 0.001 & & & $<0.001$ \\
\hline$<50 \%$ & $34(28.1)$ & 15 (18.5) & $19(47.5)$ & & $17(18.9)$ & $15(65.2)$ & \\
\hline$\geq 50 \%$ & $87(71.9)$ & $66(81.5)$ & $21(52.5)$ & & $73(81.1)$ & $8(34.8)$ & \\
\hline Hypertension & & & & 0.404 & & & 0.112 \\
\hline No & $67(55.4)$ & $47(58.0)$ & $20(50.0)$ & & $46(51.1)$ & $16(69.6)$ & \\
\hline Yes & $54(44.6)$ & $34(42.0)$ & $20(50.0)$ & & $44(48.9)$ & $7(30.4)$ & \\
\hline Diabetes mellitus & & & & 0.390 & & & 0.675 \\
\hline No & 79 (63.2) & 55 (67.9) & $24(60.0)$ & & 59 (65.6) & $14(60.9)$ & \\
\hline Yes & $42(34.7)$ & $26(32.1)$ & $16(40.0)$ & & $31(34.4)$ & $9(39.1)$ & \\
\hline Hyperlipidemia & & & & 0.653 & & & 0.076 \\
\hline No & $76(62.8)$ & $52(64.2)$ & $24(60.0)$ & & $61(67.8)$ & $11(47.8)$ & \\
\hline Yes & $45(37.2)$ & $29(35.8)$ & $16(40.0)$ & & $29(32.2)$ & $12(52.2)$ & \\
\hline
\end{tabular}

${ }^{*} p<0.001$, paired t-tests.

\section{DISCUSSION}

In this study, the incidence of PTSD in AMI patients following PCI was $33.1 \%$ during the acute stage and $20.4 \%$ during the athome recovery stage 3 months after discharge. Compared with the recovery period, the incidence of PTSD in the acute phase was higher in AMI patients after emergency PCI. A systematic review and meta-analysis showed that the incidence of PTSD after acute coronary syndromes was approximately $12 \%$, with a prevalence rate from 0 to $32 \%$ in each study (Edmondson et al., 2012).
The differences between these observations and data available in the literature could be attributed to the differences in the methods used to evaluate PTSD and the sample size. In this study, the AMI patients that had emergency PCI during the acute and convalescent stages had a higher incidence of PTSD, which was probably affected by the COVID-19 pandemic (i.e., increased isolation) during the assessment period. Because of COVID-19, AMI patients following PCI worried that they, their family members, and friends might be infected. Therefore, they experienced more psychological pressure and were more 


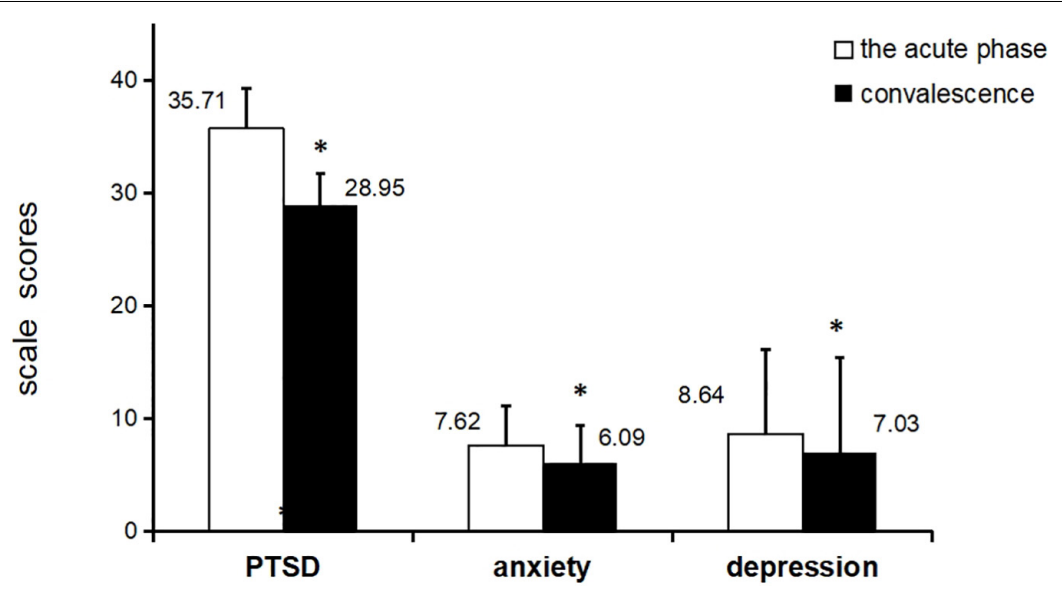

FIGURE 1 | The average scores of PTSD, anxiety, and depression in acute and convalescent phase * $<<0.001$, paired t-test, PTSD=post traumatic stress disorder.

probable to develop PTSD (Edmondson et al., 2012; Vindegaard and Benros, 2020). Although the proportion of patients with PTSD decreased slightly during the recovery period, patients were not fully disengaged from the traumatic event. Therefore, AMI is a persistent potential threat, and patients might experience AMI-related symptoms after onset, which might last for many years (Wikman et al., 2008). These observations suggest that medical staff should pay more attention to the early mental and psychological health of AMI patients after emergency PCI and if they have PTSD symptoms. If required, psychological and

TABLE 2 | Determination of risk factors for PTSD during acute stages.

\begin{tabular}{|c|c|c|c|c|}
\hline \multirow[t]{2}{*}{ Variables } & \multicolumn{2}{|c|}{ Univariate analysis } & \multicolumn{2}{|c|}{ Multifactor analysis } \\
\hline & OR (95\% Cl) & $P^{*}$ & OR $(95 \% \mathrm{Cl})$ & $P^{*}$ \\
\hline \multicolumn{5}{|l|}{ Age } \\
\hline$<61.2$ & 1.00 (Ref.) & & 1.00 (Ref.) & \\
\hline$\geq 61.2$ & $0.18(0.08-0.41)$ & $<0.001$ & $0.23(0.05-1.15)$ & 0.073 \\
\hline \multicolumn{5}{|l|}{$\begin{array}{l}\text { Degree of } \\
\text { education }\end{array}$} \\
\hline $\begin{array}{l}\text { Junior high } \\
\text { school and } \\
\text { below }\end{array}$ & 1.00 (Ref.) & & 1.00 (Ref.) & \\
\hline $\begin{array}{l}\text { Senior high } \\
\text { school and } \\
\text { above }\end{array}$ & $5.93(2.59-13.57)$ & $<0.001$ & $3.06(0.62-15.01)$ & 0.169 \\
\hline \multicolumn{5}{|l|}{ Smoking } \\
\hline No & 1.00 (Ref.) & & 1.00 (Ref.) & \\
\hline Yes & $4.42(1.95-10.00)$ & $<0.001$ & $2.77(0.75-10.22)$ & 0.125 \\
\hline \multicolumn{5}{|l|}{ DTB (min) } \\
\hline$<92.6$ & 1.00 (Ref.) & & 1.00 (Ref.) & \\
\hline$\geq 92.6$ & $11.94(4.85-29.43)$ & $<0.001$ & $34.83(8.61-141.00)$ & $<0.001$ \\
\hline \multicolumn{5}{|l|}{ LVEF } \\
\hline$<50 \%$ & 1.00 (Ref.) & & 1.00 (Ref.) & \\
\hline$\geq 50 \%$ & $0.25(0.11-0.58)$ & 0.001 & $0.08(0.02-0.30)$ & $<0.001$ \\
\hline
\end{tabular}

${ }^{*} p<0.001$, paired t-tests.

DTB, door-to-balloon; LVEF, left ventricular ejection fraction. other medical treatments should be administered to patients that have obvious PTSD symptoms to promote early recovery.

Multivariate analysis of PTSD during the acute stage showed that the longer the DTB time, the increased risk of PTSD. In 2013, The guidelines emphasized that DTB duration for STEMI patients that received PCI should be $<90$ min (O'gara et al., 2013). The guidelines for myocardial revascularization published in 2014 suggested that the appropriate DTB time was $<60 \mathrm{~min}$ (Kolh and Windecker, 2014). Therefore, DTB time is the most critical time index during the treatment procedure (O'gara et al., 2013; Kolh and Windecker, 2014), and reopening the blood supply in the shortest time to achieve myocardial level reperfusion could save more functional myocardium. The

TABLE 3 | Determination of risk factors for PTSD during convalescent stages.

\begin{tabular}{|c|c|c|c|c|}
\hline \multirow[t]{2}{*}{ Variables } & \multicolumn{2}{|c|}{ Univariate analysis } & \multicolumn{2}{|c|}{ Multifactor analysis } \\
\hline & OR (95\% Cl) & $P^{*}$ & OR $(95 \% \mathrm{Cl})$ & $P^{*}$ \\
\hline \multicolumn{5}{|l|}{ Age } \\
\hline$<61.2$ & 1.00 (Ref.) & & 1.00 (Ref.) & \\
\hline$\geq 61.2$ & $0.20(0.07-0.60)$ & 0.004 & $0.40(0.07-2.23)$ & 0.297 \\
\hline \multicolumn{5}{|l|}{$\begin{array}{l}\text { Degree of } \\
\text { education }\end{array}$} \\
\hline $\begin{array}{l}\text { Junior high } \\
\text { school and } \\
\text { below }\end{array}$ & 1.00 (Ref.) & & 1.00 (Ref.) & \\
\hline $\begin{array}{l}\text { Senior high } \\
\text { school and } \\
\text { above }\end{array}$ & $4.57(1.70-12.31)$ & 0.003 & $2.35(0.46-12.07)$ & 0.307 \\
\hline \multicolumn{5}{|l|}{ Smoking } \\
\hline No & 1.00 (Ref.) & & 1.00 (Ref.) & \\
\hline Yes & $8.21(2.57-26.18)$ & $<0.001$ & $5.12(1.30-20.16)$ & 0.019 \\
\hline \multicolumn{5}{|l|}{ LVEF } \\
\hline$<50 \%$ & 1.00 (Ref.) & & 1.00 (Ref.) & \\
\hline$\geq 50 \%$ & $0.12(0.05-0.34)$ & $<0.001$ & $0.08(0.02-0.28)$ & $<0.001$ \\
\hline
\end{tabular}


TABLE 4 | Comparison of the positive rates of PTSD between anxiety and depression subgroups during the acute stage.

\begin{tabular}{llcl}
\hline Index & \multicolumn{2}{c}{ PTSD during acute stage $(\boldsymbol{n}=\mathbf{1 2 1})$} & \multirow{2}{*}{$\boldsymbol{P}^{\star}$} \\
\cline { 2 - 3 } & No $(\boldsymbol{n}=\mathbf{8 1})$ & Yes $(\boldsymbol{n}=\mathbf{4 0})$ & \\
\hline Anxiety & & $<0.001$ \\
Yes $(n=65)$ & $59(90.8)$ & $6(9.2)$ & \\
No $(n=56)$ & $22(39.3)$ & $34(60.7)$ & $<0.001$ \\
Depression & & & \\
No $(n=65)$ & $60(92.3)$ & $5(7.7)$ & \\
Yes $(n=56)$ & $21(37.5)$ & $35(62.5)$ & \\
\hline
\end{tabular}

${ }^{*}$ Chi-square tests.

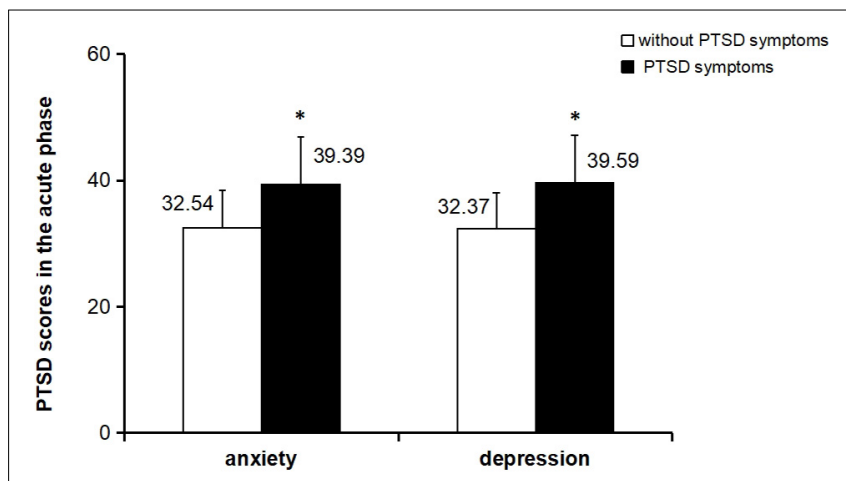

FIGURE 2 | Comparison of PTSD scores between anxiety and depression subgroups in the acute phase ${ }^{*} p<0.001$ paired t-test.

severity of AMI is a risk factor for PTSD (Xia Liu et al., 2019). A shorter DTB might remove the patient from danger more quickly; therefore, reducing the psychological burden as well as the probability of PTSD, anxiety, and depression. Therefore, rapid revascularization and reduction of DTB time during the treatment of AMI patients is critical to reduce the incidence of PTSD.

The results of this study indicated that LVEF $<50 \%$ was a risk factor for PTSD. LVEF is an important indicator for the evaluation of cardiac function (Jia et al., 2011). The degree of myocardial ischemia in STEMI patients depends on the time of vascular opening and delayed vascular opening results in massive cardiac cell death, myocardial infarction, left ventricular remodeling, and a continuous decrease in LVEF. A larger scope for myocardial necrosis has an increased negative impact on cardiac function and blood circulation dynamics, and therefore, generates more somatic symptoms, and places increased psychological stress on AMI patients. Newman et al. (2011) surveyed 241 patients with acute coronary syndromes and reported that those with PTSD symptoms (18\%) were higher than those without PTSD symptoms (82\%) (LVEF: 53.0 vs. 46.1\%). In addition, (Sawatari et al., 2016) found that LVEF level was a useful to predict of PTSD severity. Therefore, early active treatment should be carried out to improve the cardiac function of severe AMI patients to promote the early recovery, reduce psychological stress, and prevent, or reduce PTSD, or both.
In this study, patients that were smokers were more probable to develop PTSD, which agreed with previous research (Calhoun et al., 2008). AMI patients were admitted to the Coronary Care Unit after emergency PCI and were not allowed to smoke, and eventually had to stop smoking. Because nicotine enhances cognition and attention, giving up smoking might increase the cognitive and attention deficit associated with PTSD. Compared with smokers without PTSD, smokers with PTSD had a higher rate of relapse aspiration and withdrawal syndrome during cessation, and their tolerance for pain associated with the withdrawal threshold was low, and the trauma of withdrawal was more sensitive (Dedert et al., 2012; Ashare et al., 2014; Tidey and Miller, 2015). Therefore, smoking cessation guidance for AMI patients should be strictly implemented during the acute hospitalization stage, and the possibility of PTSD should be assessed during the convalescent stage. In addition, during the convalescent stage, more support and intervention should be administered to AMI patients to help them stop smoking.

The development of PTSD in AMI patients was closely related to anxiety and depression during the acute and convalescent stages. AMI patients had increased anxiety and depression with different degrees before and after PCI surgery, probably because they were excessively worried about the risks of PCI itself and the potential complications and other uncertain factors (Langvik and Hjemdal, 2015). Previous studies concluded that depression and PTSD were reciprocal risk factors (Whitehead et al., 2006; Roberge et al., 2010). Therefore, when AMI patients display any signs of anxiety and depression after emergency PCI, nursing staff should closely monitor and evaluate if the patients develop PTSD during the acute and convalescent stages. When symptoms of anxiety, depression, and PTSD coexist, nursing staff should assess if symptoms of serious complications occur and offer early psychological intervention to prevent PTSD and to improve the prognosis of AMI patients.

Although age and education was not significant risk factors of PTSD in the multivariable model, young age or higher education level was associated with PTSD risk during the acute stage and the convalescent stage in the univariate analysis. Consistent with the previous research, patients with cancer who were younger reported to be a greater risk of PTSD (Abbey et al., 2015). Lin et al. (2017) showed the highly educated participants were likely to have PTSD. Therefore, AMI patients with young age or high education levels should be provided with health care to prevent PTSD after emergency percutaneous coronary intervention.

This study has some limitations. First, this study was a singlecenter study with a small sample size, therefore, caution should be employed when generalizing from the findings, and further research with a larger sample is needed to validate them. Second, the convalescent stage analyzed in this study was 3 months after discharge, which was relatively short. Therefore, future studies should have a follow-up for a longer recovery period to evaluate the occurrence of PTSD in AMI patients following PCI more accurately. In addition, the measurement methods used in this study were questionnaires that were completed by the patients or obtained by phone. Therefore, the possibility that the patients were subjective when answering questions could not be ruled out, which might not reflect their real psychological state. 


\section{CONCLUSION}

In this study, a higher incidence of PTSD was reported in AMI patients during the acute and convalescent stages after emergency PCI. The occurrence of PTSD was closely related to a long DTB time, LVEF $<50 \%$, and smoking, and the AMI patients with PTSD had a higher comorbidity rate with anxiety and depression than those without PTSD. Therefore, attention should be paid to the mental health problems of AMI patients during the acute and convalescent stages after emergency PCI. During the acute stage, emergency care should be strengthened for AMI patients with early emergency PCI, DTB time should be shortened to reduce the incidence of PTSD, and smoking, poor heart function, and anxiety and depression symptoms should be closely monitored. During the convalescent stage, follow-up should be improved to closely monitor if AMI patients have PTSD symptoms after discharge, and suitable interventions should be conducted to reduce the adverse health outcomes associated with PTSD.

Future research should focus on the development of tools to screen and assess PTSD in AMI patients to determine the incidence and severity of PTSD more accurately. The followup time should be extended to assess PTSD at different time points after AMI to determine whether patients have PTSD after 6 months, 1 year, or a longer period after discharge from hospital. In addition, qualitative research should be designed to explore the causes of PTSD from the patients perspective to adopt more personalized interventions to prevent or reduce the occurrence of PTSD, reduce the adverse outcomes caused by PTSD, and improve the quality of life of patients.

\section{DATA AVAILABILITY STATEMENT}

The original contributions presented in the study are included in the article/supplementary material, further inquiries can be directed to the corresponding author/s.

\section{REFERENCES}

Abbey, G., Thompson, S. B., Hickish, T., and Heathcote, D. (2015). A meta-analysis of prevalence rates and moderating factors for cancer-related post-traumatic stress disorder. Psychooncology 24, 371-381. doi: 10.1002/pon.3654

Ashare, R. L., Falcone, M., and Lerman, C. (2014). Cognitive function during nicotine withdrawal: Implications for nicotine dependence treatment. Neuropharmacology 76(Pt B), 581-591. doi: 10.1016/j.neuropharm.2013.04.034

Birk, J., Kronish, I., Chang, B., Cornelius, T., Abdalla, M., Schwartz, J., et al. (2019). The Impact of Cardiac-induced Post-traumatic Stress Disorder Symptoms on Cardiovascular Outcomes: Design and Rationale of the Prospective Observational Reactions to Acute Care and Hospitalizations (ReACH) Study. Health Psychol. Bull. 2019, 310-320. doi: 10.5334/hpb.16

Burg, M. M., and Soufer, R. (2016). "Post-traumatic Stress Disorder and Cardiovascular Disease". Curr. Cardiol. Rep. 18:94.

Calhoun, P. S., Elter, J. R., Jones, E. J., Kudler, H., and Straits-Tröster, K. (2008). "Hazardous alcohol use and receipt of risk-reduction counseling among U.S. veterans of the wars in Iraq and Afghanistan". J. Clin. Psychiatry 69, 1686-1693. doi: 10.4088/jcp.v69n1103

Castilla, C., and Vázquez, C. (2011). Stress-related symptoms and positive emotions after a myocardial infarction: a longitudinal analysis. Eur. J. Psychotraumatol. 2:8082. doi: 10.3402/ejpt.v2i0.8082

\section{ETHICS STATEMENT}

The studies involving human participants were reviewed and approved by the Ethics Committee of the Second Affiliated Hospital of Guangzhou Medical University. The patients/participants provided their written informed consent to participate in this study. Written informed consent was obtained from the individual(s) for the publication of any potentially identifiable images or data included in this article.

\section{AUTHOR CONTRIBUTIONS}

$\mathrm{XC}, \mathrm{JW}, \mathrm{YG}, \mathrm{XL}, \mathrm{YD}$, and $\mathrm{CM}$ : conceptualization. $\mathrm{XC}$ and JW: methodology and writing-original draft preparation. YD and $\mathrm{XL}$ : formal analysis and investigation. JW and $\mathrm{CM}$ : writing-review and editing. XC and CM: funding acquisition and supervision. YG and XL: resources. XC and JW equally contributed to the writing of this article. All authors contributed to the article and approved the submitted version.

\section{FUNDING}

This study was funded by the Traditional Chinese Medicine Bureau of Guangdong Province (No. 20211245).

\section{ACKNOWLEDGMENTS}

We would like to thank the participants in this study, and other health care professionals in the Department of Cardiovascular Diseases, The Second Affiliated Hospital of Guangzhou Medical University that supported the implementation of this study. We would also like to thank the help in the revision of this manuscript from Shaoling Wang, School of Nursing, The Hong Kong Polytechnic University, Hong Kong SAR, China.

Dedert, E. A., Calhoun, P. S., Harper, L. A., Dutton, C. E., Mcclernon, F. J., and Beckham, J. C. (2012). "Smoking withdrawal in smokers with and without posttraumatic stress disorder". Nicotine Tob. Res. 14, 372-376. doi: 10.1093/ntr/ ntr 142

Dinenberg, R. E., Mccaslin, S. E., Bates, M. N., and Cohen, B. E. (2014). "Social support may protect against development of posttraumatic stress disorder: findings from the Heart and Soul Study". Am. J. Health Promot. 28, 294-297. doi: 10.4278/ajhp.121023-QUAN-511

Edmondson, D., and von Känel, R. (2017). "Post-traumatic stress disorder and cardiovascular disease". Lancet Psychiatry 4, 320-329.

Edmondson, D., Richardson, S., Falzon, L., Davidson, K. W., Mills, M. A., and Neria, Y. (2012). "Posttraumatic stress disorder prevalence and risk of recurrence in acute coronary syndrome patients: a meta-analytic review". PLoS One 7:e38915. doi: 10.1371/journal.pone.0038915

Edmondson, D., Rieckmann, N., Shaffer, J. A., Schwartz, J. E., Burg, M. M., Davidson, K. W., et al. (2011). "Posttraumatic stress due to an acute coronary syndrome increases risk of 42-month major adverse cardiac events and all-cause mortality". J. Psychiatr. Res. 45, 1621-1626. doi: 10.1016/j.jpsychires.2011.07. 004

Guler, E., Schmid, J. P., Wiedemar, L., Saner, H., Schnyder, U., and von Känel, R. (2009). "Clinical diagnosis of posttraumatic stress disorder after myocardial infarction". Clin. Cardiol. 32, 125-129. doi: 10.1002/clc.20384 
Hari, R., Begré, S., Schmid, J. P., Saner, H., Gander, M. L., and von Känel, R. (2010). "Change over time in posttraumatic stress caused by myocardial infarction and predicting variables". J. Psychosom. Res. 69, 143-150. doi: 10.1016/j.jpsychores. 2010.04.011

Jia, E. Z., Xu, Z. X., Yang, Z. J., Zhu, T. B., Wang, L. S., Cao, K. J., et al. (2011). "Severity of coronary atherosclerosis is an independent predictor of the left ventricular ejection fraction". Clin. Exp. Pharmacol. Physiol. 38, 109-112. doi: 10.1111/j.1440-1681.2010.05474.x

Känel, R., Hari, R., Schmid, J. P., Wiedemar, L., Guler, E., Barth, J., et al. (2011). "Non-fatal cardiovascular outcome in patients with posttraumatic stress symptoms caused by myocardial infarction". J. Cardiol. 58, 61-68. doi: 10.1016/ j.jjcc.2011.02.007

Kolh, P., and Windecker, S. (2014). "ESC/EACTS myocardial revascularization guidelines 2014". Eur. Heart J. 35, 3235-3236.

Konrad, B., Hiti, D., Chang, B. P., Retuerto, J., Julian, J., and Edmondson, D. (2017). "Cardiac patients' perceptions of neighboring patients' risk: influence on psychological stress in the ED and subsequent posttraumatic stress". BMC Emerg. Med. 17:33. doi: 10.1186/s12873-017-0144-3

Langvik, E., and Hjemdal, O. (2015). "Symptoms of depression and anxiety before and after myocardial infarction: The HUNT 2 and HUNT 3 study". Psychol. Health Med. 20, 560-569. doi: 10.1080/13548506.2014.9 89864

Ledermann, K., von Känel, R., Barth, J., Schnyder, U., Znoj, H., Schmid, J. P., et al. (2020). "Myocardial infarction-induced acute stress and post-traumatic stress symptoms: the moderating role of an alexithymia trait - difficulties identifying feelings". Eur. J. Psychotraumatol. 11:1804119. doi: 10.1080/20008198.2020. 1804119

Levine, G. N., Bates, E. R., Bittl, J. A., Brindis, R. G., Fihn, S. D., Fleisher, L. A., et al. (2016). "2016 ACC/AHA Guideline Focused Update on Duration of Dual Antiplatelet Therapy in Patients With Coronary Artery Disease: A Report of the American College of Cardiology/American Heart Association Task Force on Clinical Practice Guidelines: An Update of the 2011 ACCF/AHA/SCAI Guideline for Percutaneous Coronary Intervention, 2011 ACCF/AHA Guideline for Coronary Artery Bypass Graft Surgery, 2012 ACC/AHA/ACP/AATS/PCNA/SCAI/STS Guideline for the Diagnosis and Management of Patients With Stable Ischemic Heart Disease, 2013 ACCF/AHA Guideline for the Management of ST-Elevation Myocardial Infarction, 2014 AHA/ACC Guideline for the Management of Patients With Non-ST-Elevation Acute Coronary Syndromes, and 2014 ACC/AHA Guideline on Perioperative Cardiovascular Evaluation and Management of Patients Undergoing Noncardiac Surgery". Circulation 134, e123-e155.

Li, H., Wang, L., Shi, Z., Zhang, Y., Wu, K., and Liu, P. (2010). "Diagnostic utility of the PTSD Checklist in detecting ptsd in Chinese earthquake victims". Psychol. Rep. 107, 733-739. doi: 10.2466/03.15.20.PR0.107.6.7 33-739

Liang, X., Zhu, Y., and Fang, Y. (2020). "COVID-19 and post-traumatic stress disorder: A vicious circle involving immunosuppression". CNS Neurosci. Ther. 26, 876-878. doi: $10.1111 / \mathrm{cns} .13431$

Lin, Y. H., Kao, C. C., Wu, S. F., Hung, S. L., Yang, H. Y., and Tung, H. Y. (2017). Risk factors of post-traumatic stress symptoms in patients with cancer. J. Clin. Nurs. 26, 3137-3143.

Liu, X., Lin, P., and Wang, Y. (2019). "Research progress of post-traumatic stress disorder in patients with acute myocardial infarction". Modern Clin. Nurs. 18, 53-57. doi: 10.1186/s13054-016-1208-6

Meli, L., Alcántara, C., Sumner, J. A., Swan, B., Chang, B. P., and Edmondson, D. (2019). "Enduring somatic threat perceptions and post-traumatic stress disorder symptoms in survivors of cardiac events". J. Health Psychol. 24, 1817-1827. doi: $10.1177 / 1359105317705982$

Newman, J. D., Muntner, P., Shimbo, D., Davidson, K. W., Shaffer, J. A., and Edmondson, D. (2011). "Post-traumatic stress disorder (PTSD) symptoms predict delay to hospital in patients with acute coronary syndrome". PLoS One 6:e27640. doi: 10.1371/journal.pone.0027640

Oflaz, S., Yüksel, Ş, Şen, F., Özdemiroğlu, F., Kurt, R., Oflaz, H., et al. (2014). Does Illness Perception Predict Posttraumatic Stress Disorder in Patients with Myocardial Infarction? Noro Psikiyatr. Ars. 51, 103-109.
O’gara, P. T., Kushner, F. G., Ascheim, D. D., Casey, D. J., Chung, M. K., de Lemos, J. A., et al. (2013). "2013 ACCF/AHA guideline for the management of STelevation myocardial infarction: executive summary: a report of the American College of Cardiology Foundation/American Heart Association Task Force on Practice Guidelines". Circulation 127, 529-555.

Perkins-Porras, L., Joekes, K., Bhalla, N., Sutherland, C., and Pollard, M. (2015). "Reporting of Posttraumatic Stress Disorder and Cardiac Misconceptions Following Cardiac Rehabilitation". J. Cardiopulm. Rehabil. Prev. 35, 238-245. doi: 10.1097/HCR.0000000000000100

Reed, G. W., Rossi, J. E., and Cannon, C. P. (2017). "Acute myocardial infarction". Lancet 389, 197-210.

Roberge, M. A., Dupuis, G., and Marchand, A. (2010). "Post-traumatic stress disorder following myocardial infarction: prevalence and risk factors". Can. J. Cardiol. 26, e170-e175. doi: 10.1016/s0828-282x(10)70386-x

Saito, Y., and Kobayashi, Y. (2019). "Percutaneous coronary intervention strategies in patients with acute myocardial infarction and multivessel disease: Completeness, timing, lesion assessment, and patient status". J. Cardiol. 74, 95-101. doi: 10.1016/j.jjcc.2019.04.001

Sawatari, H., Ohkusa, T., Rahamawati, A., Ishikawa, K., Tsuchihashi-Makaya, M., Ohtsuka, Y., et al. (2016). "Left Ventricular Ejection Fraction Predicts Severity of Posttraumatic Stress Disorder in Patients With Implantable CardioverterDefibrillators". Clin. Cardiol. 39, 263-268. doi: 10.1002/clc.22521

Singh, A., Agrawal, S., Gargya, S., Saluja, S., Kumar, A., Kumar, A., et al. (2017). "Posttraumatic stress disorder after myocardial infarction and coronary artery bypass grafting". Int. J. Crit. Illn. Inj. Sci. 7, 84-90. doi: 10.4103/IJCIIS.IJCIIS_ 27_17

Stevanović, A., Frančišković, T., and Vermetten, E. (2016). Relationship of earlylife trauma, war-related trauma, personality traits, and PTSD symptom severity: a retrospective study on female civilian victims of war. Eur. J. Psychotraumatol. 2016:730964. doi: 10.3402/ejpt.v7.30964

Sumner, J. A., Kubzansky, L. D., Elkind, M. S., Roberts, A. L., Agnew-Blais, J., Chen, Q., et al. (2015). "Trauma Exposure and Posttraumatic Stress Disorder Symptoms Predict Onset of Cardiovascular Events in Women". Circulation 132, 251-259. doi: 10.1161/circulationaha.114.014492

Tidey, J. W., and Miller, M. E. (2015). Smoking cessation and reduction in people with chronic mental illness. BMJ 2015:351h4065.

Vindegaard, N., and Benros, M. E. (2020). COVID-19 pandemic and mental health consequences: Systematic review of the current evidence. Brain Behav. Immun. 2020, 89531-89542.

Whitehead, D. L., Perkins-Porras, L., Strike, P. C., and Steptoe, A. (2006). "Post-traumatic stress disorder in patients with cardiac disease: predicting vulnerability from emotional responses during admission for acute coronary syndromes". Heart 92, 1225-1229. doi: 10.1136/hrt.2005.070946

Wikman, A., Bhattacharyya, M., Perkins-Porras, L., and Steptoe, A. (2008). "Persistence of posttraumatic stress symptoms 12 and 36 months after acute coronary syndrome". Psychosom. Med. 70, 764-772. doi: 10.1097/PSY. 0b013e3181835c07

Xiao, S. (2008). Clinical research design. Beijing: Peking University Medical Press.

Conflict of Interest: The authors declare that the research was conducted in the absence of any commercial or financial relationships that could be construed as a potential conflict of interest.

Publisher's Note: All claims expressed in this article are solely those of the authors and do not necessarily represent those of their affiliated organizations, or those of the publisher, the editors and the reviewers. Any product that may be evaluated in this article, or claim that may be made by its manufacturer, is not guaranteed or endorsed by the publisher.

Copyright (C) 2021 Cao, Wu, Gu, Liu, Deng and Ma. This is an open-access article distributed under the terms of the Creative Commons Attribution License (CC BY). The use, distribution or reproduction in other forums is permitted, provided the original author(s) and the copyright owner(s) are credited and that the original publication in this journal is cited, in accordance with accepted academic practice. No use, distribution or reproduction is permitted which does not comply with these terms. 